Resenha

\title{
O papel do Poder Local no combate à pandemia de COVID-19
}

\author{
Review \\ The role of local government in combating the COVID-19 pandemic
}

Reseña

El papel del gobierno local en la lucha contra la pandemia de COVID-19

André Dias Pereira ${ }^{1}$

\section{Resumo}

A obra Poder Local em tempos de COVID-19 analisa o impacto das restrições provocadas pela COVID-19 no funcionamento da democracia local e da democracia participativa, abordam-se os efeitos da legislação COVID-19 no emprego público, nas finanças locais, na contratação pública e na digitalização da administração pública; analisa a cooperação territorial e institucional que se verificou entre os municípios e o poder estadual, o Serviço Nacional de Saúde e as Freguesias. No final, considera os riscos e potencialidades que podem estar associados à fase de recuperação, deixando-se um alerta para os perigos de descontrolo orçamental nos municípios e no sector empresarial local, para a importância de se combaterem os riscos de corrupção associados a esta fase com medidas sólidas aptas a assegurar uma governação sustentável e transparente, e para a necessidade de se fazer da recuperação uma oportunidade para se assegurar a efetiva implementação nos municípios dos Objetivos de Desenvolvimento Sustentável da ONU.

\section{Palavras-chave}

Poder Local. COVID-19. Políticas Públicas.

\begin{abstract}
This work analyzes the impact of the restrictions caused by COVID-19 on the functioning of local democracy and participatory democracy, addressing the effects of the COVID-19 legislation on public employment, local finance, public procurement and the digitization of public administration; analyzes the territorial and institutional cooperation that took place between the municipalities and the State power, the National Health Service and the local Authorities. In the end, it considers the risks and potentialities that may be associated with the recovery phase, leaving an alert to the dangers of lack of budgetary control in municipalities and in the municipal enterprises sector, to the importance of combating the risks of corruption associated with this phase with solid measures capable of ensuring sustainable and transparent governance, and the need to turn recovery into an opportunity to ensure the effective implementation of the UN Sustainable Development Goals in municipalities.
\end{abstract}

\section{Keywords}

Municipal Authorities. COVID-19. Public Policies.

\footnotetext{
${ }_{1}^{1}$ Doutor em Direito Civil; diretor, Centro de Direito Biomédico, Faculdade de Direito, Universidade de Coimbra, Coimbra, Portugal. https://orcid.org/0000-0003-4793-3855. E-mail: andreper@fd.uc.pt
} 


\section{Resumen}

Este trabajo analiza el impacto de las restricciones provocadas por COVID-19 sobre el funcionamiento de la democracia local y la democracia participativa, abordando los efectos de la legislación COVID-19 sobre el empleo público, las finanzas locales, la contratación pública y la digitalización de la administración pública; analiza la cooperación territorial e institucional que se dio entre los municipios y el poder estatal, el Serviço Nacional de Sanidad y los ayuntamientos. Al final, considera los riesgos y potencialidades que se pueden asociar a la fase de recuperación, dejando una alerta a los peligros de la falta de control presupuestario en los municipios y en el sector empresarial local, a la importancia de combatir los riesgos de corrupción asociados a esta fase, con medidas sólidas capaces de asegurar una gobernanza sostenible y transparente, y la necesidad de convertir la recuperación en una oportunidad para asegurar la implementación efectiva de los Objetivos de Desarrollo Sostenible de la ONU en los municipios.

\section{Palabras clave}

Poder Local. COVID-19. Políticas Públicas.

A obra Poder Local em tempos de COVID-19 - em dois volumes $(1,2)$ - reúne textos de autores de proveniência científica diversa: Ciência Política, Direito, Sociologia, Comunicação, Economia, Auditoria, Políticas públicas, Engenharia informática, entre outras e de profissões diversas: autarcas, professores, magistrados, advogados, investigadores, técnica superior de município. Encontramos autores portugueses de origens geográficas distintas: Aveiro, Bragança, Coimbra, Minho, Lisboa. Assim, para além da alta representatividade geográfica, esta obra reúne um total de 20 capítulos, nos quais participam 32 autores com um amplo conhecimento e experiência nas lides autárquicas e é uma obra com equilíbrio de género. Poderá ser injusto destacar alguém deste naipe, mas todos compreendem que refira o nome de José Tavares, Juiz Conselheiro, Presidente do Tribunal de Contas e do Conselho de Prevenção da Corrupção, dos meus colegas - professores da Faculdade de Direito da Universidade de Coimbra, Pedro Gonçalves e Fernanda Paula Oliveira - e do Professor Pedro Pitta Barros, ilustre economista da saúde e que foi colega do signatário deste texto no Conselho Nacional de Ética para as Ciências da Vida (CNECV), de 2015 a 2021. Autores que garantem a alta qualidade desta obra!

Parabéns aos coordenadores Luís Filipe Mota Almeida, do Direito Público; Luís de Sousa, da Ciência Política; e Manuel Ferreira Ramos, jurista e consultor da Associação Nacional de Assembleias Municipais. Trata-se de uma publicação temporalmente acertada e de conteúdo de excelência! Um marco fundamental nesta área do saber e com importância para o Direito, as Políticas Públicas e a ação concreta dos decisores políticos.

Esta é a primeira obra que, relativamente às autarquias locais, analisa o impacto da crise sanitária, económica e social provocada pela COVID-19. Está dividida em 2 volumes e 
contém a Parte I sobre A Qualidade da Democracia Local em Tempos de COVID-19. Aqui se revelam as limitações das plataformas eletrónicas para o verdadeiro debate político; demonstram-se as dificuldades (Luís Mota de Almeida) do exercício do direito de oposição durante as pandemias e a presidencialização (Marco Caldeira) do Executivo - também ele elevado a responsável pela proteção civil pelo artigo $35 .^{\circ}$ da Lei n. $27 / 2006$ - Lei da Proteção Civil -, na sua reforma de 2015.

Por seu turno, a Democracia participativa ficou limitada nestes mais de 18 meses (Roberto Falanga e Fiovani Allegretti), numa pandemia que é para além de uma patologia do corpo, uma patologia da sociedade. Ainda assim, os autores deste capítulo revelam casos de sucesso e inovação, na área da democracia participativa, em Lisboa, Cascais e Valongo... que merecem leitura atenta.

Na Parte II - A Governação Local em Tempos de COVID-19 - encontramos textos sobre O papel dos municípios na resposta à crise sanitária, social e económica, de Carlos José Batalhão, que destaca o papel excecional dos municípios portugueses no combate à crise pandémica, designadamente no plano da atuação sanitária, da atuação informativa, da atuação financeira e da contratação pública, oferecendo refeições e outros apoios sociais e socioeconómicos, isenções e benefícios fiscais e apoios diretos às empresas. Por coincidência, o pacote legislativo de descentralização entrou em vigor neste ano e meio da pandemia - trata-se da transferência do Estado para os Municípios várias competências em matéria de saúde e de educação, entre outras, que resulta da Lei n. ${ }^{\circ}$ 50/2018 de 16 de agosto (Lei-quadro da transferência de competências para as autarquias locais e para as entidades intermunicipais) - e, no específico domínio da saúde, o Decreto-Lei n. ${ }^{\circ}$ 23/2019 de 30 de janeiro. Como afirma o autor "fique para memória futura (...) a relevância crucial das autarquias locais, nomeadamente em épocas de emergência..." e remata: "O Estado de Direito democrático não é nada sem autarquias locais."

O livro avança com perspectivas jurídico-financeiras (Hugo Flores da Silva e Joaquim Freitas da Rocha), que nos dão conta da flexibilização em vários domínios (contratação, prestação de contas, simplificação de procedimentos, etc...). Os autores terminam com algumas palavras de cautela e exigência de maior rigor e racionalidade na despesa pública. Segue-se uma explanação sobre a contratação pública local no contexto da pandemia COVID-19 de Pedro Gonçalves, de que se destaca a explicação sobre o regime excecional do ajuste direto. A terminar esta parte e o primeiro volume, Susana Ferreira dos Santos e Melanie Neiva Santos escrevem sobre o Emprego público municipal: teletrabalho e proteção 
de dados em tempos de COVID-19. Aqui se anota que, por exemplo na Câmara Municipal de Lisboa, havia no dia 1 de março de 2021 - 41\% dos trabalhadores em teletrabalho.

Passamos ao Vol. II e entramos na Parte III - Cooperação Territorial e Institucional em resposta à COVID-19. Desde a cooperação entre o poder local e o poder estadual (Ana Fernanda Neves) - cujo quadro legal de importa reforçar, até ao papel das Freguesias (unidade administrativa mais próxima das populações, ao nível de bairro nas cidades ou de um conjunto próximo de populações, nas zonas rurais) (Cláudia Costa e Tânia Maia) que ofereceram respostas que importa não esquecer: aquisição e distribuição de equipamentos de proteção individual, atividades de desinfeção, higienização e limpeza, disponibilização ou financiamento de testes à COVID-19, distribuição de refeições e bens alimentares a pessoas carenciadas e alunos, atribuição ou empréstimo de computadores e equipamentos informáticos, apoios logísticos à população, linhas de apoio, campanhas de sensibilização, apoios ao comércio local, apoios ao plano de vacinação contra a COVID-19... Um conjunto vasto de atividades que este poder autárquico de grande proximidade e com recursos financeiros muito limitados, mas que fez toda a diferença na vida das populações durante a crise pandémica. Enfim, uma miríade de atividades que revela a imaginação e dedicação das Juntas de Freguesia ao bem comum! Um pilar do poder democrático que importa qualificar, robustecer e promover!

Pedro Pitta Barros apresenta-nos a hospitalização domiciliária como solução de futuro, na qual os municípios também se devem envolver. Lança o desafio aos municípios de criarem a sua unidade de Hospitalização Domiciliária. Apresenta ainda uma interessante análise na qual conclui: i) os concelhos com uma proporção maior na população do grupo etário com mais de 65 anos tiveram um maior choque associado à pandemia; ii) a densidade populacional do concelho - concelhos mais densamente povoados foram sendo mais duramente atingidos pela pandemia; iii) concelhos com maior proporção de desempregados apresentam maior peso de COVID-19.

Finalmente, Manuel Ferreira Ramos explica o papel da ANAM e das Assembleias Municipais em tempos de pandemia.

A Parte IV - Risco de Má Governação e outros Desafios em tempos de COVID-19 e de Recuperação - é escrita a pensar já na recuperação e na fase pós-pandémica. Aqui se coloca em evidência, pela mão de José Tavares, Presidente do Tribunal de Contas, e de Ana Paula Gil Garcês, o imperativo de Boa governação, gestão de riscos e transparência em contexto pandémico, realçando o papel decisivo do Tribunal de Contas: "aciona o plano 
de contingência, mapeia riscos no emprego de dinheiros públicos e recomenda medidas específicas de controlo." E afirmam: "quanto maior é a tormenta, maior é a exigência colocada a todos os tripulantes da nau!" Com efeito, recordam: "O montante das múltiplas medidas COVID reportado pelo Ministério das Finanças cifra-se na escala dos milhares de milhões de euros".

Tiago Serrão discorre sobre o funcionamento dos órgãos colegiais autárquicos, sobretudo anotando a passagem da obrigatoriedade de reuniões, deliberações e votações presenciais, para a admissibilidade de meios telemáticos. O autor propõe que esta medida excecional seja adotada para futuro com carácter permanente. À semelhança do CPA, os meios telemáticos vieram para ficar nos órgãos colegiais autárquicos. É uma proposta que merece ponderação. O autor vai mais longe e defende a utilização de meios eletrónicos para a realização de convocatórias e a regulação da votação por escrutínio secreto. Tenho dúvidas de que esse seja o caminho, pois o contacto humano é importante para a vivência da polis e as decisões dos órgãos políticos beneficiam dessa dimensão corpórea e presencial. Constitui um tema que merece atenta reflexão.

Pedro Camões aborda também o tema do risco do descontrolo orçamental em tempos de COVID-19. Deste texto, importa logo realçar que Portugal está na parte de baixo da tabela no que respeita ao peso comparativo das despesas da Administração Regional e Local no total da despesa pública. Temos que descentralizar mais e transferir mais verbas para as autarquias - é condição de desenvolvimento do território e das populações! Um contributo modesto para a mudança pode vir do Fundo de Solidariedade da União Europeia, no qual os municípios são as únicas entidades beneficiárias desses fundos. O caminho seria, pois, que "cada governo local deve financiar, a partir de recursos ou receitas próprias as despesas sobre as quais decide." Cuidado, porém, pois o princípio da solidariedade nacional implica transferências financeiras entre regiões.

Júlia Gonçalves coloca-nos em alerta ao escrever Pré-insolvência municipal em tempos de COVID-19, mas apresenta propostas de solução, defendendo a responsabilidade subsidiária do município, na exata medida em que exerce o controlo em cadeia.

Georgina Morais apresenta um estudo sobre A necessidade de implementar mecanismos de auditoria interna para uma recuperação sustentável nas autarquias.

Um conjunto de autores - José Fidalgo, João António Joana Abreu, Tânia Correia, Jorge Cerol e Ricardo Reis - colocam em destaque Os Objetivos de desenvolvimento sustentável enquanto bússola da recuperação pós- COVID-19. É de aplaudir a convocação 
deste instrumento-bússola internacional, para um mundo mais sustentável e com máximo respeito pelos direitos humanos. Finalmente, Fernanda Paula Oliveira escreve sobre Perspetivas e desafios urbanísticos num mundo pós-COVID: breves reflexões, texto no qual questiona se o eventual regresso ao campo ou a fuga às cidades terá consequências no direito urbanismo. A autora alerta para que não se deve voltar ao urbanismo em "mancha de óleo"... antes densificar as médias e pequenas cidades. Este é um desafio para os municípios e para as regiões!

Por fim, destaco algumas ideias que muito me marcaram na leitura destes dois volumes:

1) A ligação entre o Poder Local e a Academia. A promoção de uma relação dialógica de enriquecimento comum e a produção de saber para conduzir, com mais qualidade, os destinos coletivos.

2) A colocação da saúde em todas as políticas em lugar cimeiro. Quer na política da União Europeia, do Estado, das Regiões, dos Municípios... em todas as políticas: de educação, de urbanismo, de turismo, de economia e indústria, de ambiente, etc. Devemos introduzir os indicadores de saúde e ambientais nas métricas económicas e não apenas o PIB! E ter uma visão holística da saúde, fugindo do sistema hospitalocêntrico e não cair noutro centralismo dos cuidados de saúde primários. Com efeito, como a pandemia está a demonstrar, a saúde está para além dos edifícios físicos e seus profissionais.

3) Daí, a compreensão da importância da saúde pública e da saúde mental no sistema de saúde. Temos que reivindicar esta centralidade - mesmo para além dos períodos pandémicos.

4) $O$ não afunilamento das discussões aos estereótipos do século $X X$, designadamente na frágil dicotomia público-privado, mas antes a compreensão da necessidade do envolvimento de todos os setores e a devida dignificação do setor social.

5) A preocupação com a corrupção, o desvio de fundos e a má gestão, quer durante a pandemia, quer após a pandemia. É um imperativo ético de todos nós.

\section{Referências}

1. Almeida LFM de, Sousa L de, Ramos MF (coord.). Poder Local em tempos de COVID19. Vol. 1, A Qualidade da Democracia Local e Governação em Tempos de COVID-19. Coimbra: Almedina; 2021. ISBN: 978-972-40-97512. 
2. Almeida LFM de, Sousa L de, Ramos MF (coord.). Poder Local em tempos de COVID19. Vol. 2, A Cooperação Territorial e Institucional no Combate à Pandemia e os Desafios da Recuperação, Coimbra: Almedina; 2021. ISBN: 978-972-40-97169.

Como citar este artigo

Dias Pereira A. O papel do Poder Local no combate à pandemia de COVID-19. Cadernos Ibero-Americanos de Direito Sanitário. 2021 jul./set.;10(3):235-241.

https://doi.org/10.17566/ciads.v10i3.822 